\title{
Regulatory Submission Date
}

National Cancer Institute

\section{Source}

National Cancer Institute. Regulatory Submission Date. NCI Thesaurus. Code C70863.

A date on the submission form or cover letter, whichever is the latest. 